\title{
PENGEMBANGAN DAN PEMEKARAN USAHA PERTANIAN, INDUSTRI KECIL-MENENGAH, EKONOMI, KOMUNIKASI, SERTA DAYA WISATA DAN BUDAYA DAERAH JAWA BARAT DI ERA GLOBALISASI
}

\author{
Suhanda $^{1}$, Erwan Komara ${ }^{2}$, R. Didin Kusdian ${ }^{3}$, Biller Pandjaitan ${ }^{4}$, Ony Djogo ${ }^{5}$, Asep Dion \\ Nugraha $^{6}$, Demsi Minar ${ }^{7}$, Yushar Kadir ${ }^{8}$, Djoko Pitoyo ${ }^{9}$, Cecep Deni Mulyadi ${ }^{10}$, Tia Sugiri ${ }^{11}$, \\ Ketut Abimanyu $\mathbf{M}^{12}$, Wisnu Wijaya ${ }^{13}$, Rodiah ${ }^{14}$, Fitri Sya'bandyah ${ }^{15}$, Dody Kusmana ${ }^{16}$, S. \\ W. Pitara ${ }^{17}$, Ivany Syarief ${ }^{18}$, Slamet Risnanto ${ }^{19}$, Hanhan Hanafiah Solihin ${ }^{20}$, Teguh Nurhadi \\ Suharsono $^{21}$, Nunung Sanusi ${ }^{22}$, Roni Tabroni ${ }^{23}$, Triyani Hayati ${ }^{24}$, Tata Zaenal Mutaqin ${ }^{25}$, Didi \\ Supardi $^{26}$, Finny Sri Redjeki ${ }^{27}$, Anita Syafariah ${ }^{28}$, Nenny Hendajany ${ }^{29}$ \\ 1,3,8, 9, 10, 11, 12, 13, 14, 15, 16, 17, 18, 19, 20, 21 Fakultas Teknik, Universitas Sangga Buana \\ 2, 6, 22, 23 Fakultas Ilmu Soial Ilmu Politik, Universitas Sangga Buana \\ ${ }^{4,5,7}$ Program Pascasarjana, Universitas Sangga Buana \\ 24, 25, 26, 27, 28,29 Fakultas Ekonomi, Universitas Sangga Buana \\ ${ }^{1}$ korespondensi : suhanda@usbypkp.ac.id
}

\begin{abstract}
ABSTRAK
Desa Sunten Jaya, Kecamatan Lembang, Kabupaten Bandung Barat, merupakan desa yang memiliki banyak potensi. Namun potensi tersebut belum didukung dengan adanya bimbingan dan pengarahan untuk memaksimalkan potensi tersebut. Dengan menggunakan pendekatan wawancara dan diskusi, kelompok Pengabdian Kepada Masyarakat Universitas Sangga Buana bekerjasama dengan Universitas Kebangsaan mencoba untuk membantu mengembangkan potensi tersebut. Salah satu solusi yang ditawarkan adalah dengan membuat Website Penjualan untuk memasarkan hasil perkebunan dan industry kecil-menengah Desa Sunten Jaya. Dengan adanya kegiatan Pengabdian Kepada Masyarakat ini diharapkan dapat membantu masyarakat Desa Sunten Jaya untuk mengelola dan mengembangkan potensi desa mereka.
\end{abstract}

Kata Kunci: Pengabdian kepada Masyarakat, Potensi Desa, Website Penjualan

\begin{abstract}
Sunten Jaya Village, Lembang District, West Bandung Regency, is a village that has a lot of potential. However, this potential has not been supported by guidance and direction to maximize this potential. By using an interview and discussion approach, the Sangga Buana University Community Service group in collaboration with the University of Kebangsaan tries to help develop this potential. One of the solutions offered is to create a Sales Website to market the results of plantations and small and medium industries in Sunten Jaya Village. With this Community Service activity, it is hoped that it can help the people of Sunten Jaya Village to manage and develop the potential of their village.
\end{abstract}

Keywords: Community Service, Village Potential, e-Commerce

\section{PENDAHULUAN}

Desa Sunten Jaya, Kecamatan Lembang,

Kabupaten Bandung Barat, merupakan desa yang memiliki banyak potensi, diantaranya adalah sebagai berikut: potensi perkebunan, peternakan, usaha di bidang industri kecil dan menengah, potensi daerah wisata Curug Cibodas, serta potensi budaya daerah Jawa Barat. Namun, dengan begitu banyaknya 
potensi yang dimiliki, belum didukung dengan adanya bimbingan dan pengarahan untuk memaksimalkan potensi tersebut.

Oleh karena itu, dosen Universitas Sangga Buana melakukan kegiatan Pengabdian kepada Masyarakat (PKM) Bersama dengan dosen Universitas Kebangsaan Republik Indonesia di desa tersebut, dengan harapan dapat membantu masyarakat untuk mengembangkan potensi desanya tersebut. Dengan adanya PKM ini, diharapkan ke depannya Desa Suntenjaya dapat lebih maju dan berkembang melalui potensi desa yang dimilikinya, sehingga akan berdampak positif juga kepada masyarakat desa itu sendiri.

\section{METODE}

Sehubungan dengan banyaknya potensi desa yang perlu digarap, maka dalam melaksanakan PKM ini, para dosen dibagi ke dalam beberapa kelompok disesuaikan dengan bidang ilmunya masing-masing, kemudian dikaitkan dengan potensi-potensi yang ada di Desa Suntenjaya tersebut.

Setelah itu, setiap kelompok kemudian melaksanakan tugasnya masing-masing dengan menggunakan dua cara/metode, yaitu: melakukan kunjungan kepada masyarakat dan mewawancarainya, serta melakukan presentasi dan diskusi dengan masyarakat.

Kunjungan dan wawancara kepada masyarakat bertujuan agar para dosen bisa membaca masalah apa yang dihadapi oleh masyarakat berkaitan dengan potensi desa yang dimiliki, untuk kemudian dilakukan analisa untuk mengatasi permasalahan tersebut. Setelah analisa permasalahan didapatkan, para dosen kemudian mempresentasikan solusi untuk permasalahan potensi tersebut daam bentuk penyuluhan dan membuka ruang diskusi untuk membahasnya lebhih mendalam atau jika ada penjelasan yang belum begitu dimengerti oleh masyarakat desa.

Penyuluhan diartikan sebagai hubungan timbal balik antara dua pihak untuk mencapai pengertian tentang peranan dalam hubungan dengan masalah-masalah yang dihadapi pada waktu yang akan datang. Dari pengertian tersebut, terlihat bahwa sasaran penyuluhan adalah suatu pihak yang mempunyai masalah tentang suatu hal. Kemudian, setelah mengikuti penyuluhan, diharapkan pihak tersebut memperoleh konsep diri dan kepercayaan diri dalam memperbaiki keadaan saat ini dan masa yang akan datang. [1]

\section{HASIL DAN PEMBAHASAN}

Pada kegiatan PKM ini, para dosen dibagi ke dalam 7 kelompok sesuai dengan bidang ilmunya masing-masing, dan ketujuh kelompok tersebut kemudian diberikan tugas yang berbeda. Tugas-tugas tersebut adalah sebagai berikut:

1) Memberikan sosialisasi manfaat dan pentingnya pemasaran hasil perkebunan dan produk industri kecil dan menengah secara online di Desa Suntenjaya

2) Memantau kondisi dan lokasi pengembangan daerah pariwisata dan aset jalan, serta memberikan penjelasan tentang 
pembangunan wilayah pariwisata kepada masyarakat Desa Sunten Jaya

3) Memberikan penjelasan tentang manfaat penggunaan dan pemeliharaan mesin giling kopi serta pemanfaatan turbin air dan jaringan komunkasi, dalam pengembangan lokasi pariwisata

4) Memberikan penyuluhan tentang pengembangan industri kecil-menengah penggunaan bahan baku dan analisis perencanaan pencarian modal usaha untuk masyarakat dalam pembangunan di desa sunten jaya lembang

5) Memberikan pengarahan tentang usahausaha dalam mewujudkan pertumbuhan ekonomi pedesaan bagi masyarakat dan pendapatan sampingan bagi keluarga menuju hidup sejahtera serta pendataan pertumbuhan ekonomi mayarakat.

6) Memberikan penyuluhan masyarakat keluarga sadar hukum serta mentaati peraturan dan perundang-undangan hukum di Indonesia kepada masyarakat Desa Sunten Jaya Lembang
7) Memberikan pengarahan, penyuluhan tentang pembinaan mental dan siraman rohani serta pengembangan psykologi anak, sosial, seni, dan budaya kepada masarakat Desa Sunten Jaya Lembang.

Sebelum masing-masing kelompok melaksanakan tugasnya, terlebih dahulu dilakukan proses kunjungan dan wawancara kepada masyarakat Desa Suntenjaya, guna memeroleh informasi mengenai hal-hal yang berkaitan dengan potensi desa yang akan dikembangkan. Dari hasil kunjungan dan wawancara tersebut didapatkan informasi bahwa beberapa potensi utama yang akan dikembangkan adalah berupa hasil perkebunan, usaha industri kecil-menengah, di mana di dalamnya juga terdapat dengan usaha industri yang berkaitan dengan kebudayaan, serta potensi pengembangan Daerah Wisata Alam Curug Luhur Cibodas.

Beberapa hasil perkebunan potensial yang berada di Desa Suntenjaya, diantaranya adalah: jeruk, nanas, kopi, tomat, dan bunga matahari.

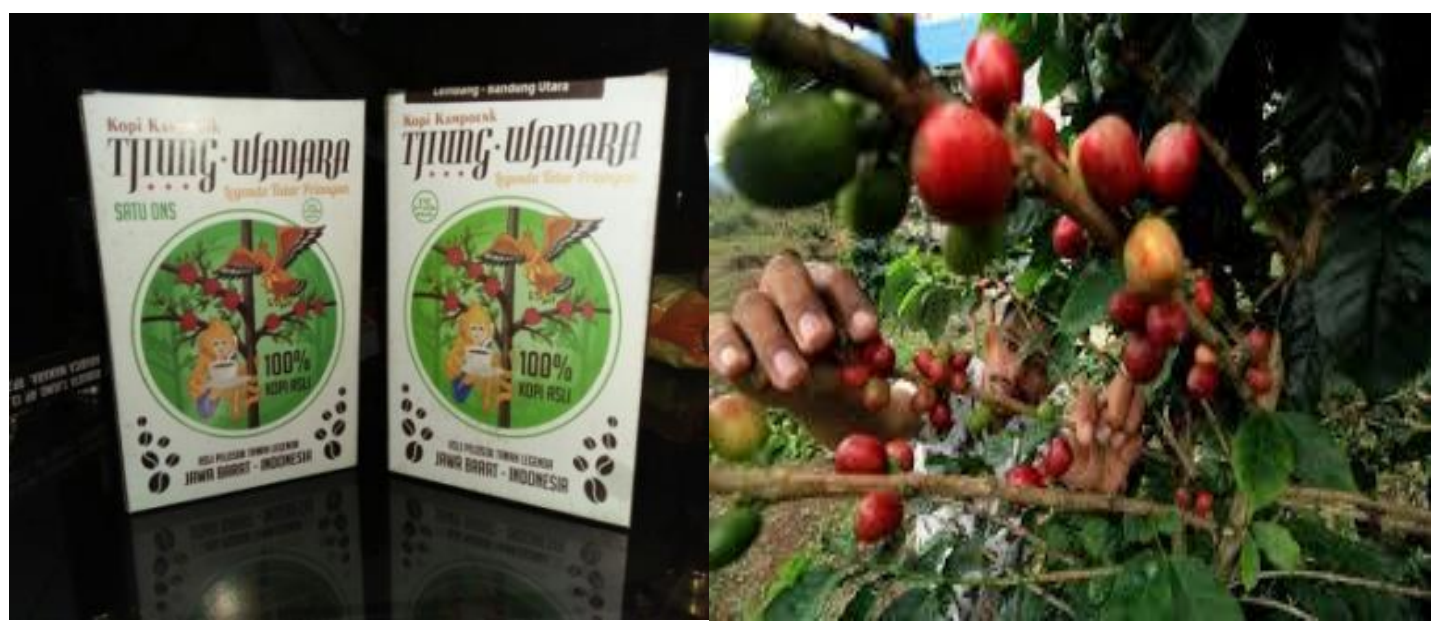

Gambar 1 : Kopi Hasil Perkebunan Desa Suntenjaya 


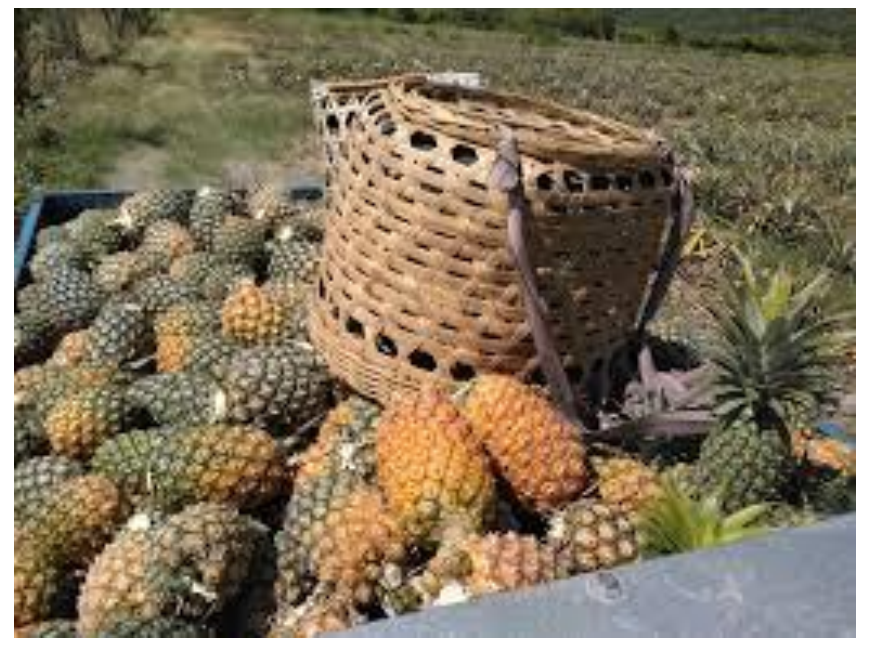

Gambar 2 : Nanas Hasil Perkebunan Desa Suntenjaya

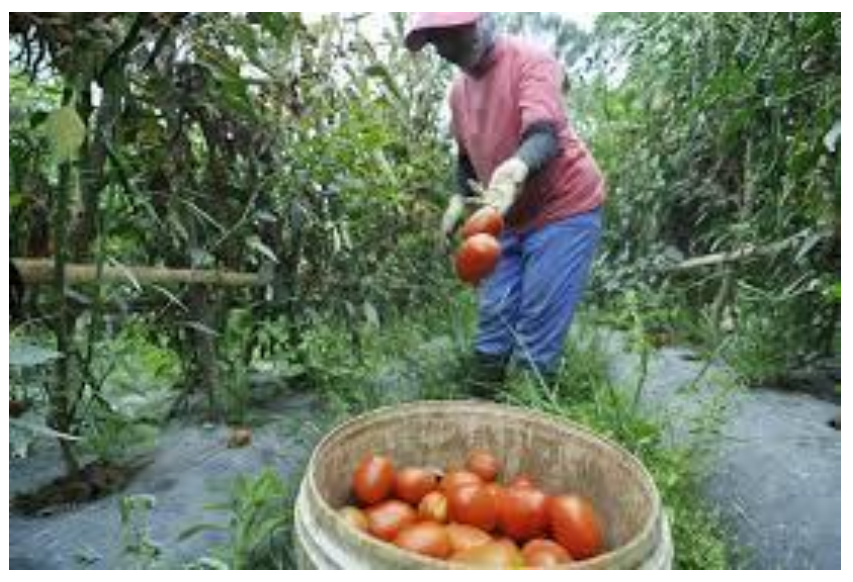

Gambar 3 : Tomat Hasil Perkebunan Desa Suntenjaya

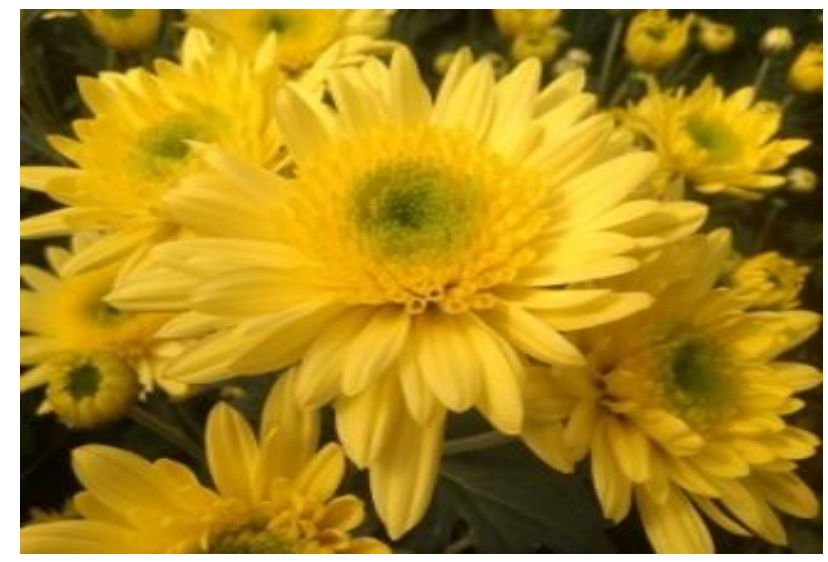

Gambar 4 : Bunga Matahari Hasil Perkebunan Desa Suntenjaya

Sementara itu, untuk hasil industri usaha kecil-menengah berupa kerajinan bunga dari limbah daun dan plastik, serta kerjainan wayang golek. Hasil industri tersebut belum termasuk industri olahan makanan ringan, seperti wajit, keripik, kue 
basah, dan kue kering. Namun, industri olahan makanan tersebut belum begitu baik proses produksinya, karena hanya dijual pada saat menjelang hari raya, dan tidak dipasarkan di toko kue, melainkan konsumen sendiri yang datang ke rumah penjual tersebut.

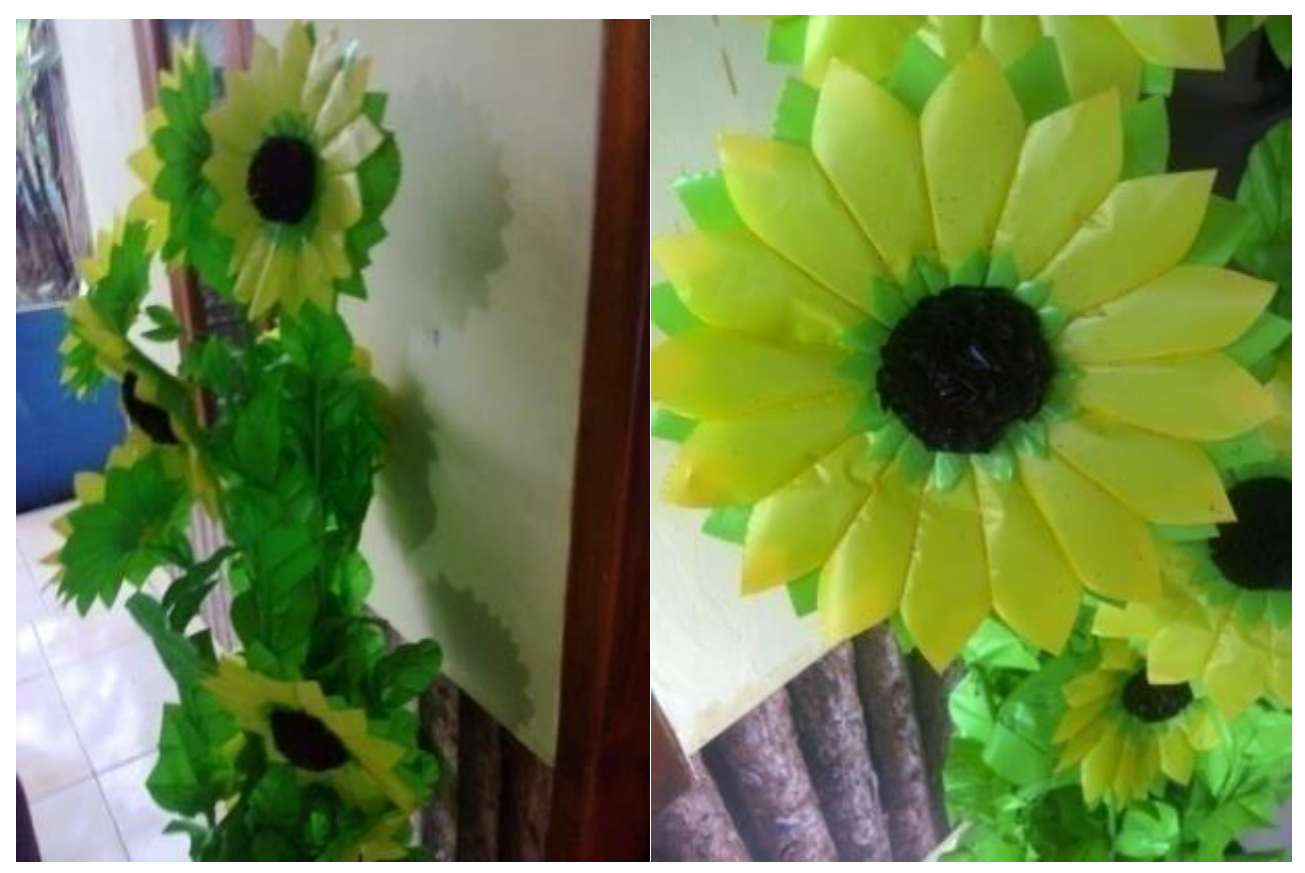

Gambar 5 : Hasil Kerajinan Bunga dari Limbah Daun dan Plastik

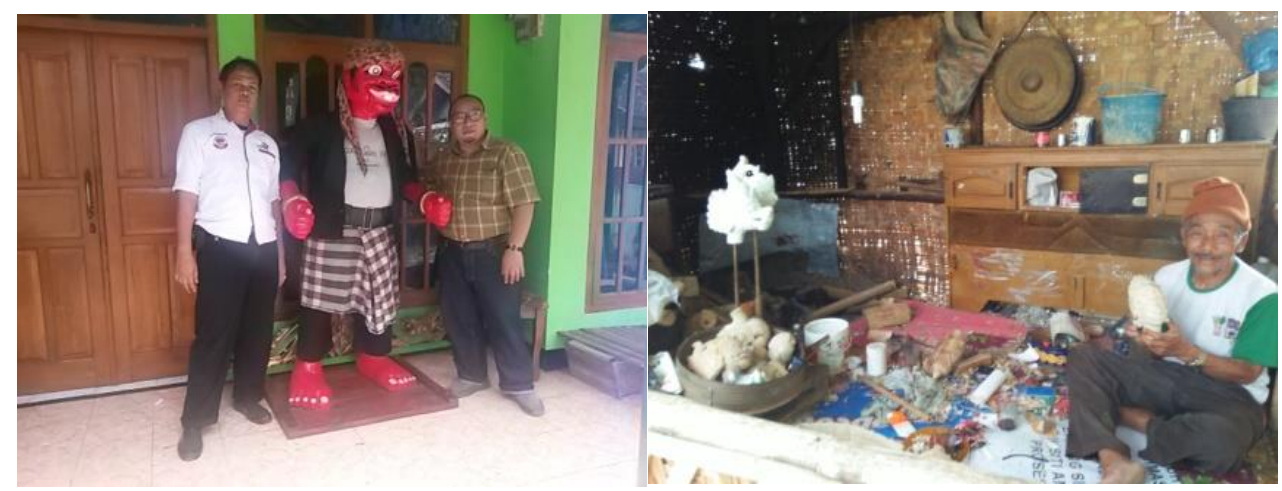

Gambar 6 : Usaha Industri Pembuatan Wayang Golek

Selain potensi hasil perkebunan dan diantaranya adalah perluasan wilayah, industri usaha kecil-menengah, terdapat pembuatan akses jalan ke lokasi wisata, juga potensi Daerah Wisata Alam Curug pembuatan turbin air, dan merenovasi Luhur Cibodas. Pengembangan potensi sarana permainan untuk pengunjung, serta daerah wisata yang akan dilakukan pengembangan daerah wisata di sekitar 
Curug Luhur Cibodas, yaitu Daerah Wisata

Batu Loceng dan Batu Kuda.
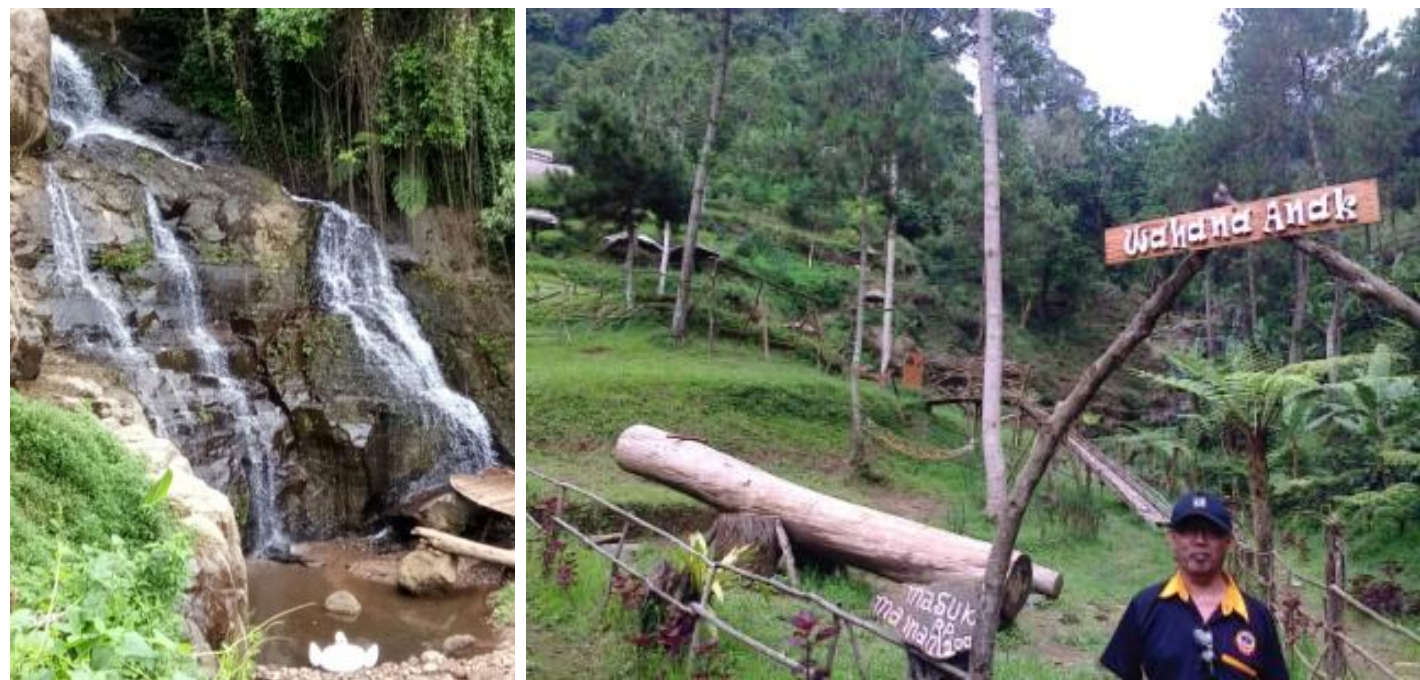

Gambar 7 : Daerah Wisata Alam Curug Luhur Cibodas

Setelah mengetahui masalah-masalah yang berkaitan potensi Desa Suntenjaya, setiap kelompok kemudian merumuskan solusi untuk permasalahan tersebut sesuai dengan tugas kelompoknya masing-masing. Solusi tersebut kemudian dipresentasikan/ disosialisasikan dalam bentuk penyuluhan ataupun diskusi sehingga masyarakat Desa Suntenjaya dapat menerima ide, saran, dan masukan sehingga dapat mengembangkan potensi-potensi yang ada di desa mereka.

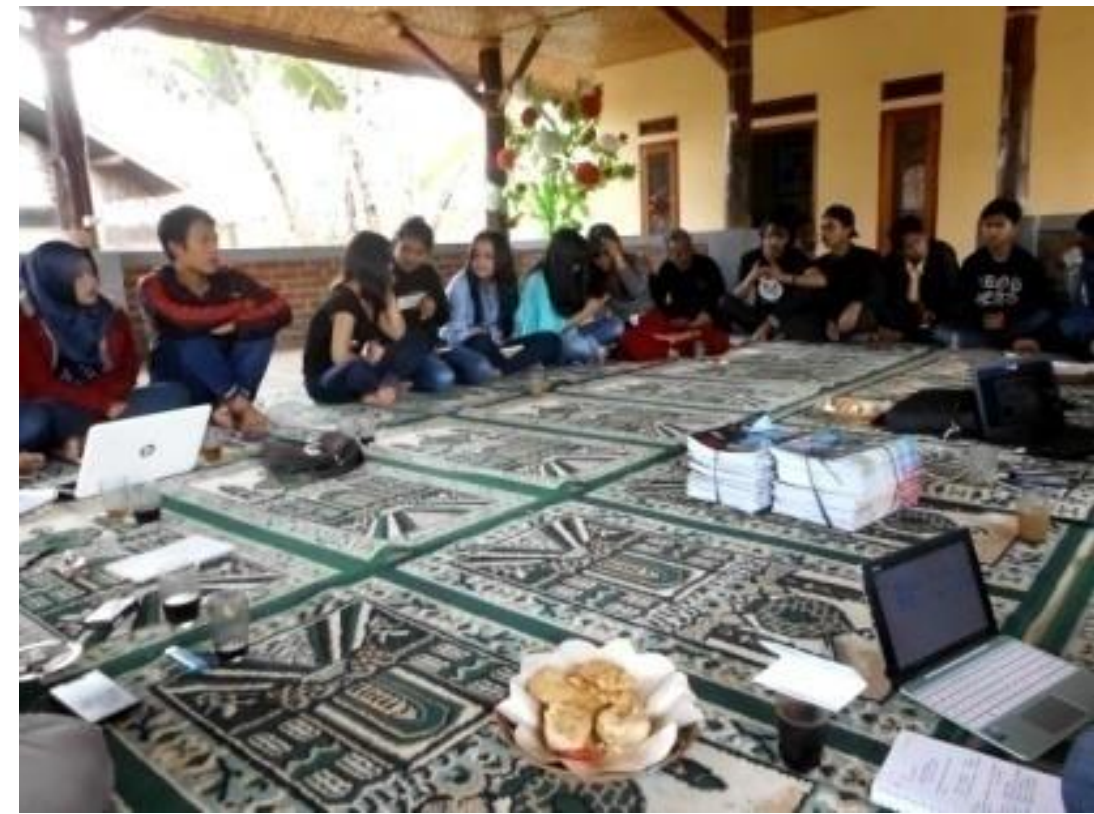

Gambar 8 : Masyarakat Desa Suntenjaya Menerima Penyuluhan 


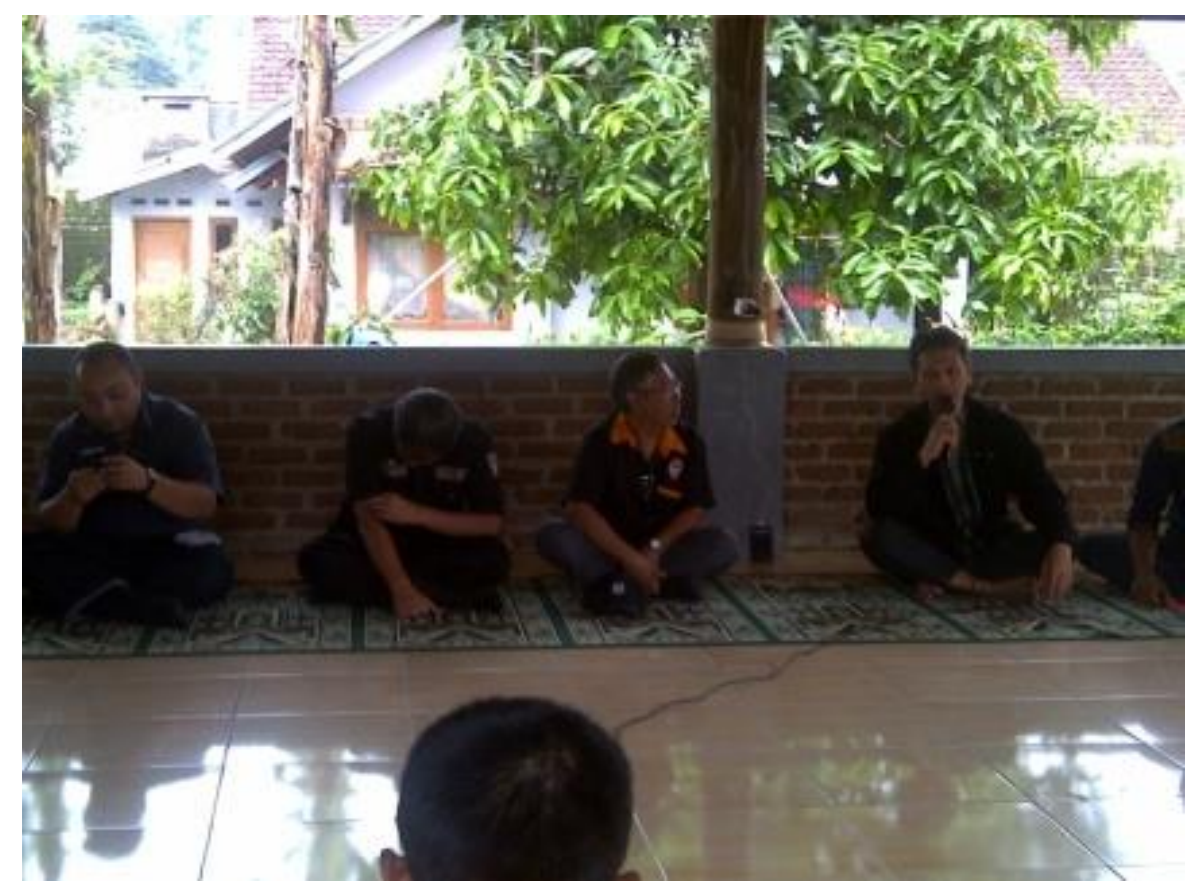

Gambar 9 : Kelompok PKM USB Memberikan Penyuluhan kepada Masyarakat Desa Suntenjaya

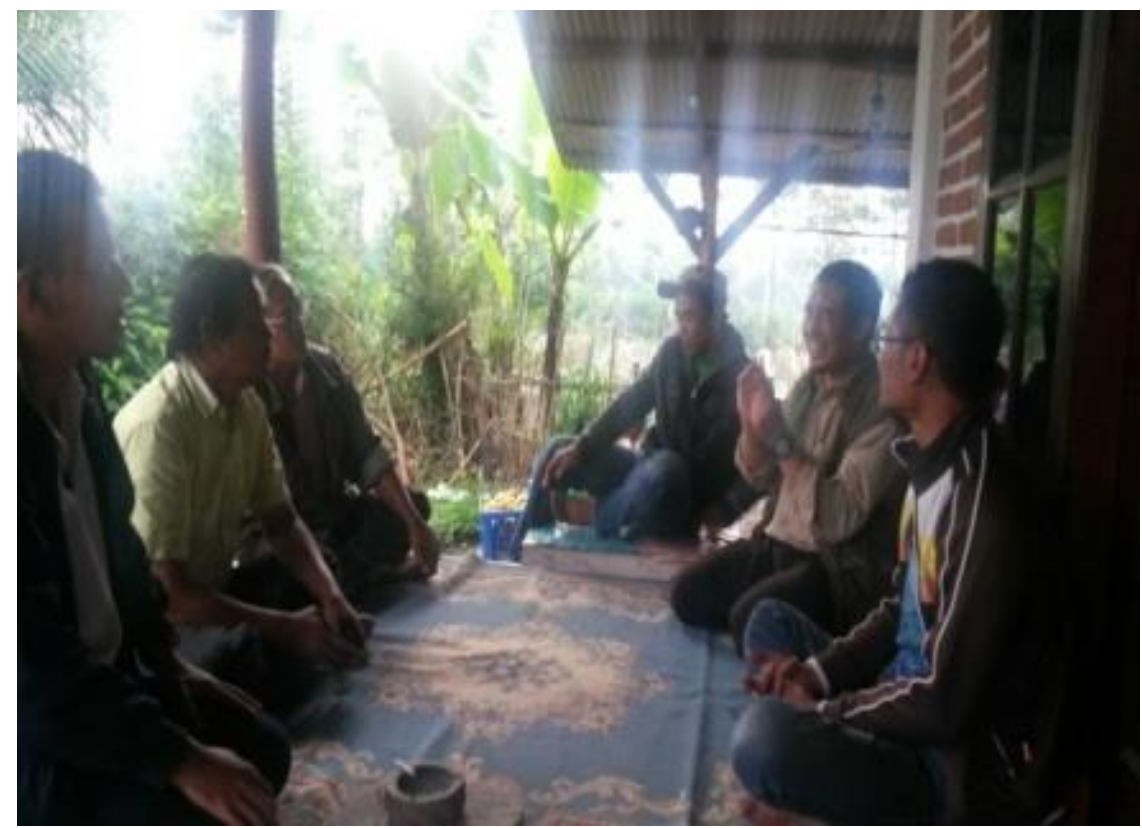

Gambar 10 : Suasana Diskusi Antara Kelompok PKM USB dengan Masyarakat Desa Suntenjaya

Selain pemberian penyuluhan dan diskusi, kelompok PKM USB juga membuatkan suatu situs Website Penjualan (e-Commerce), untuk membantu memudahkan pemasaran dan penjualan hasil perkebunan dan industri usaha kecil-menengah yang ada di Desa Suntenjaya. 
Penggunaan e-Commerce memiliki banyak keuntungan, seperti : dapat meningkatkan Market Exposure (Pangsa Pasar) dan menurunkan tingkat biaya operasional [2]. Dengan adanya website tersebut, diharapkan hasil perkebunan dan usaha kecil-menengah yang ada di Desa Suntenjaya dapat lebih dikenal oleh masyarakat luar, sehingga dapat membantu meningkatkan penjualan, yang nantinya secara otomatis dapat pula meningkatkan pendapatan masyarakat Desa Suntenjaya. Website yang dibuat berupa website sederhana, agar lebih mudah dipahami oleh masyarakat dalam penggunananya. Dalam Website ini tersedia menu Data Produk, menu Registrasi, dan menu Transaksi Pembelian.

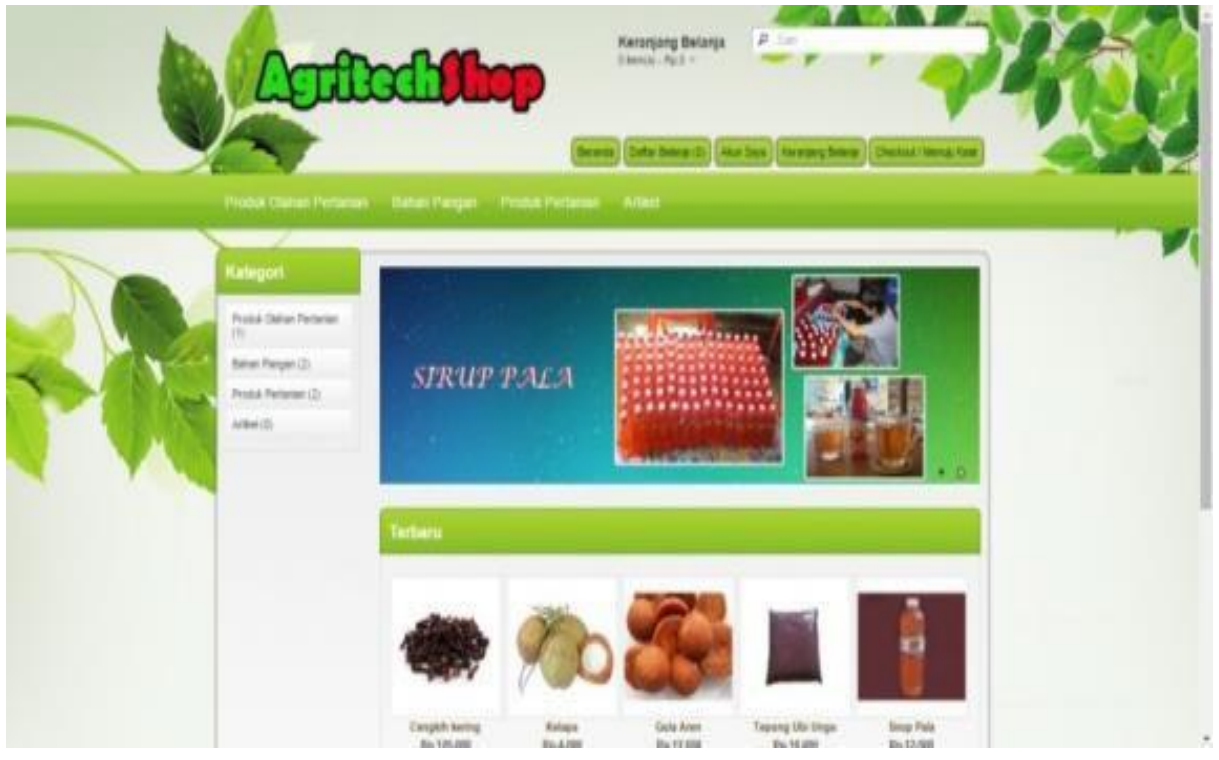

Gambar 11 : Tampilan Website Penjualan Hasil Perkebunan

\section{KESIMPULAN DAN SARAN}

Dengan berakhirnya Pengabdian Kepada Masyarakat di Desa Suntenjaya

Kecamatan Lembang Kabupaten Bandung Barat Provinsi Jawa barat, ada beberapa kesimpulan yang didapatkan, diantaraya adalah sebagai berikut:

1. Pemasaran Produk Hasil Perkebunan dan Industri Kecil Menengah, lebih cepat dipasarkan dan tidak memerlukan banyak tenaga serta tidak memerlukan biaya pemasaranyang besar karena tidak perlu mengunjungi konsumen yang membutuhkan.

2. Produk hasil perkebunan dan industri kecil-menengah lebih cepat dikenal konsumen dari jarak yang sangat jauh dari Lembang Kabupaten Bandung Barat.

3. Dengan adanya pemasaran secara online, maka masyarakat dapat memasarkannya dari rumah, dijadikan sebagai pekerjaan sampingan serta bagi anggota karang taruna, bisa melakukan pemasaran secara on-line sebagai usaha 
sampingan, yang mendapatkan keuntungan, di luar jam kegiatan organisasinya.

4. Dengan adanya pemasaran secara online, dapat dijadikan sarana untuk transaksi harga, penawaran produk, model produk, dan sebagainya, sehingga konsumen tidak diragukan lagi, dan pelanggan dapat pelayanan secara cepat sesuai dengan waktu kebutuhannya.

Sementara untuk saran-saran yang dapat diberikan adalah sebagai berikut:

1. Dengan adanya Pemasaran Produk Hasil Perkebunan dan Industri secara Online, sebaiknya jangan Hasil perkebunan dan Produk yang diproduksi dari Desa Suntenjaya saja, sebagai tambahan Hasil Perkebunan dari Desa lain juga ikut memasarkan, supaya dapat mengetahui kualitas dan harga sehhinngga Masyarakat bisa mengetahui persaingan dalam Dunia Pemasaran.

2. Sebaiknya dibutuhkan operator yang masih muda dan praktisi untuk mengoperasikan website pemasaran produk hasil perkebunan dan industri kecil menengah, supaya lebih terampil dan kerjanya cepat serta akurat sehingga dapat memenuhi kebutuhan.

3. Kepala Desa Sunten Jaya dan Koperasi sebaiknya meyediakan tempat untuk mengadakan pelatihan jaringan komputer bagi masyarakat dan anggota karang taruna untuk melakukan usahanya dan melaksanakan tugasnya secara online.

4. Untuk Pemekaran Kebudayaan sebaiknya Kepala Desa Sunten Jaya bermusyawarah dengan tokoh - tokoh budayawan setempat untuk mewujudkan dan melestarikan budaya terutama kesenian tradisional Jawa Barat.

5. Untuk pemekaran dan pengembangan daerah pariwisata, sebaiknya Kepala Desa Sunten Jaya, dibantu oleh Camat Lembang, dan didukung oleh beberapa Tokoh Masyarakat Sunten jaya melakukan Perundingan dan kerja sama dengan pihak Perhutani supaya nantinya setelah terwujud atau tercapai, tidak ada persengketaan antara Masyarakat dan pihak Perhutani, tetapi harus saling menguntungkan.

\section{DAFTAR PUSTAKA}

[1] Kholid, A. 2012. Promosi kesehatan. Jakarta : EGC

[2] Ginting. 2013. Aplikasi Penjualan Berbasis Web. (E-Commerce) menggunakan Joomla Pada Mutiara Fashion. Program Studi Sisyem Informasi Fakultas Teknik Universitas Widyatama Bandung. 